\title{
Pulsed LASER for Testing Silicon Strip Detectors
}

\author{
Mario Vaz \\ LAFEX/CBPF, DEL/UFRJ
}

Selcuk Cihangir and Petros Rapidis

Fermi National Accelerator Laboratory

P.O. Box 500, Batavia, Illinois 60510

July 1993 


\section{Disclaimer}

This report was prepared as an account of work sponsored by an agency of the United States Government. Neither the United States Government nor any agency thereof, nor any of their employees, makes any warranty, express or implied, or assumes any legal liability or responsibility for the accuracy, completeness, or usefulness of any information, apparatus, product, or process disclosed, or represents that its use would not infringe privately owned rights. Reference herein to any specific commercial product, process, or service by trade name, trademark, manufacturer, or otherwise, does not necessarily constitute or imply its endorsement, recommendation, or favoring by the United States Government or any agency thereof. The views and opinions of authors expressed herein do not necessarily state or reflect those of the United States Government or any agency thereof. 
FERMILAB

D0 Note 1681

May 28, 1993

\title{
Pulsed LASER for Testing Silicon Strip Detectors
}

\author{
Mario $\mathrm{Vaz}^{12}$ \\ LAFEX/CBPF , DEL/UFRJ \\ Selcuk Cihangir and Petros Rapidis \\ Fermi National Accelerator Laboratory, Batavia, IL 60510
}

\section{Introduction}

This D0 Note describes a pulsed LASER setup for testing silicon strip detectors at the Silicon Detector Facility (SiDet) of Fermilab supporting the related projects and, in particular, the D0 Silicon Tracker Upgrade[1]. It will be used in the measurements of the efficiency of individual strips and their coupling. The LASER wavelength is $1060 \mathrm{~nm}$, at which the absorption length in silicon is about $2 \mathrm{~mm}[2]$. The LASER setup is capable of producing light pulses with rise time of less than $1 \mathrm{~ns}$, allowing the measurement of charge pulse shaping at individual strips and their capacitive couplings. Due to the high power outuput of the LASER, safety considerations are included. Also discussed are precautions for the safety of the LASER itself, and how to limit the light to an area smaller than $50 \mu \mathrm{m}$ of diameter.

\section{LASER Setup}

The schematics of the setup and the laser circuit are shown in Figures 1 and 2, respectively.

A semiconductor LASER, EG\&G model C86125E-19, is used to emit light at 1064 $\mathrm{nm}$ wavelength, with a maximum output of $5 \mathrm{~mW}$ optical power. It is a customized EG\&G C86125 LASER in a C86129 LASER package, pigtailed to a $6.2 \mu m$ diameter, $60 \mathrm{~cm}$ long Corning Flexcore 1060[3] monomode optical fiber with a numerical aperture of 0.14 . In order to protect the fiber tip in the initial test phase, the fiber's tip was fused to the tip of another $9 \mu m$ diameter fiber terminated on the other end by an FC/PC connector. It will

\footnotetext{
${ }^{1}$ Supported by CNPq/RHAE grant 260034/91-6

${ }^{2}$ On leave during July 1991 to June 1993 from LAFEX/CBPF and DEL/UFRJ
} 
eventually be replaced by an appropriate $6.2 \mu \mathrm{m}$ diameter monomode fiber terminated by an ST connector, in order to keep the light beam as narrow as possible.

If the external bias connection to the LASER is accidentally open, a transient current can be created and it can be strong enough to damage the LASER. To prevent this possibility, an internal biased circuit, composed of resistors $\mathrm{R} 1, \mathrm{R} 2$, capacitors $\mathrm{C} 1, \mathrm{C} 2$ and a $-15 \mathrm{~V}$ ( 10 $\mathrm{mA}$ max. ) voltage from the Temperature Controller[4], was built. The variable resistor R1 adjusts the bias current level to allow a fast switching time with light output low enough not to be detected by the silicon strip detector. This can be seen in the schematics of the Figure 2.

In order to achieve sub-nanosecond switching, critical components like R5, C5, R2, C2, R6 and R7 are made in surface mount technology (SMT) and very short connections are used following an appropriate layout shown in Figure 3. Also, the SMT components were soldered on a general purpose printed circuit board to speed up the construction and to reduce the cost without considerable sacrifice in quality.

The light pulse emited by the LASER is monitored with an oscilloscope measuring the signal from the PIN diode inside the LASER, accross the resistor R7 through a BNC connector. For fast pulse detection it is necessary to observe the signal over a $50 \Omega$ load. The PIN diode bias voltage of $+5 \mathrm{~V}$ is provided by the $+15 \mathrm{~V}$ supplied by the Temperature Controller via the resistors R3, R4, and the capacitors C3, C4 inside the LASER box. At the fiber's tip the light pulse is monitored by a PIN diode EG\&G FFD-100, biased with an external $15 \mathrm{~V}$ and mounted in a BNC connector, as shown in Figure 2.

The LASER is driven by a negative voltage pulse through an SMA connector and the resistor R5, which limits the input current, the capacitor C5 which isolates the bias of the LASER and limits its driving pulse width. A Picosecond Pulse Labs (PPL) pulse generator used to drive the LASER gives positive voltage pulses[5]. An external pulse inverting transformer EG\&G T100 is used to invert the voltage pulse and also to decouple the LASER. A negative voltage pulse generator could also be used, removing this transformer. A wrong polarity drive to the LASER can damage it, although the resistor R5 and the LASER reverse Schottky diode provide some protection.

The PPL model $2000 \mathrm{D}$ provides repetitive $+40 \mathrm{~V}$ peak amplitude pulses over a $50 \Omega$ load, with a variable repetition rate from 100 to $1 \mathrm{M}$ pulses per second. The pulse can be triggered externally. The pulse duration is $1 \mathrm{~ns}$, expandable to a limit of $250 \mathrm{~ns}$, depending upon the maximum repetition rate, by attaching to the rear connector an open coaxial cable with a delay time of half the desired pulse width time. The inner conductor of this coaxial cable will be at +150 volts from the ground potential, so it must be insulated to prevent hazardous electrical discharges, both to people and the pulse generator itself. Damage to the pulse generator is possible if the maximum allowed pulse duration of $250 \mathrm{~ns}$ is exceeded.

The Programmable Attenuator is a Weinschel Engineering model AF97-59-33 with $18 \mathrm{GHz}$ bandwidth. The attenuation is numerically controlled from 0 to $59 \mathrm{db}$. The CAMAC interface that controls this attenuator is available and software is needed to implement this control in the data acquisition program that is being develloped for the Silicon Detector Test System.

The LASER's Temperature Controller is a New England Photoconductor model TC1A, a proportional-integral analog peltier controller with current limitation. The Temperature Controller senses the LASER substrate temperature and stabilizes it to a preset 
value by adjusting the LASER's Peltier current. The value choosen is $10 \mathrm{~K} \Omega$, corresponding to an operation temperature of about $25^{\circ} \mathrm{C}$. As can be seen in Figures 5 and 6, this stabilizes the LASER frequency, the optical power output and the threshold current.

The circuit is packaged in a POMONA Box model 3601, with inputs and outputs via SMA, BNC and 9 pin connectors, respectively for the driver input, PIN output and Temperature Controller connections as can be seen in Figure 3. The light comes through a monomode $6.2 \mu \mathrm{m}$ in diamater and $60 \mathrm{~cm}$ long optical fiber. The different types of connectors help to protect the LASER and the PIN diode from damage due to wrong connections. Therefore, care should be taken to use adopters because the high power of the driver pulses can irreversably damage the PIN diode.

\section{Safety Requirements}

The operation of this circuit at FERMILAB must follow the safety rules explained in the ANSI Z136.1-1986 document[6] because the LASER C86125E-19 is built with a Class III b laser, model EG\&G C86125E, which has an optical power of $50 \mathrm{~mW}$ when drived by a $120 \mathrm{~mA}$ current. But its optical coupling with the monomode optical fiber reduces the optical power to $5 \mathrm{~mW}$ at the fiber's tip, as can be seen in Figure 4.

The circuit is designed so that the maximum bias current for the LASER is below 10 $\mathrm{mA}$, as explained before. The pulse generator output is a positive $40 \mathrm{~V}$ peak, 1 ns duration pulse, with a maximum repetition rate of $1 \mathrm{MHz}$. This signal is $\mathrm{AC}$ coupled by $\mathrm{C} 5$ and $\mathrm{R} 5$ to the LASER, limiting the current to the sum of the bias current - 0 to $10 \mathrm{~mA}$ - with the pulse peak of $40 \mathrm{~V} / 250 \Omega=160 \mathrm{~mA}$, below the maximum allowed current of $200 \mathrm{~mA}$.

Under these conditions, the LASER will operate in a repetitive 1 ns pulse mode, with a peak output power of $5 \mathrm{~mW}$, or with an energy of $5 \mathrm{pJ} /$ pulse released through a small area on the tip of the monomode optical fiber with $6.2 \mu \mathrm{m}$ of diameter.

That gives at the tip of the fiber an energy density of [6]:

$$
H o=1.27 \times 5 p J /\left(6 \times 10^{-4}\right)^{2}=18 \mu J / \mathrm{cm}^{2} / p u l s e
$$

The ANSI rules specify that the maximum time exposure for an invisible LASER light is $T=10 \mathrm{~s}$. During this time the fiber tip releases $50 \mu \mathrm{J}$ of energy.

The maximum permissible exposure for a repetitive pulse train with frequency $f=$ $1 M H z$ and duration $t=1 n s$, is given by section 8.2.2.2 and Table 5 of Reference 5 as:

$50 \times \mathrm{Ho}$

$$
M P E=9 \times T^{3 / 4} \times(f \times T)^{-1 / 4}=9 \times 10^{3 / 4} \times\left(10^{6} \times 10\right)^{-1 / 4}=900 \mu J / \mathrm{cm}^{2} / \text { pulse } \approx
$$

The LASER operation seems safe under ANSI rules, even if the pulse width is increased to the limits of $50 \mathrm{~ns}$ at $1 \mathrm{MHz}$, or $250 \mathrm{~ns}$ at $100 \mathrm{KHz}$. Furthermore with a numerical aperture of 0.14 of the fiber, at $1 \mathrm{~cm}$ of distance from the fiber tip surface the light spreads over an area of $2.8 \mathrm{~mm}$ of diameter, $(2800 / 6.2)^{2}$ times greater than the fiber tip's area, reducing the ligth power density by a factor of $\approx 2 \times 10^{5}$.

In normal operation, both the fiber tip and silicon strip detectors will be enclosed in a dark box in order to block the light from the room. To obey FERMILAB's safety rules, a warning label will be posted on the box's door[7]. 


\section{Using the LASER setup}

The beam of ligth is emitted from the tip of the fiber with a diameter of $6.2 \mu \mathrm{m}$ and a numerical aperture of 0.14 . This means that the light opens as a truncated cone with an angle of 8 degrees, and one base of the cone has a radius larger than the radius of the other base, by an amount of 0.14 times the height of the cone, as shown in Figure 7 .

Let us assume that we can position the fiber's tip $100 \mu \mathrm{m}$ away from the silicon strip under test. Then the light cone opens from a diameter of $6.2 \mu \mathrm{m}$ at the tip of the fiber to $6.2+2 \times 100 \times 0.14=34 \mu \mathrm{m}$ at the surface of the silicon detector.

Assuming the silicon wafer 300 microns deep, and the refractive index of silicon :

$n=\sin \beta / \sin \alpha=\sqrt{\varepsilon_{r}}=\sqrt{11.3}=3.42 \quad(\sin \beta=0.14)$

The angle of the light cone inside the silicon is :

$\alpha=\arcsin (\sin \beta / 3.42)=2.34$ degrees.

The rate of lateral spreading of the light per length is : $\tan \alpha=0.040$

So the light will open less in the silicon, covering at the bottom of the silicon detector, which is $300 \mu \mathrm{m}$ thick, an area with a diameter of :

$$
34+0.04 \times 2 \times 300=58 \mu m .
$$

The metalized bottom of the detector might reflect the light back to the surface of the silicon with a diameter of

$$
34+0.04 \times 2 \times 600=82 \mu m .
$$

This reflected ligth can be detected by neighboring strips of the SVX chip. But controling the current of the laser it seems to be possible to control the intensity of the beam to avoid this problem. This can be done by software, controlling the attenuation of the driving pulse.

But still remains the possibility that we will need a lens or a set of lenses like a microscope, to collimate the beam and to relax the above constraint of a precise positioning of the silicon strip detector. Another possibility is to use a positioning servo system, with a capacitive position transducer around the fiber's tip and a proportional- integral controller, to adjust automatically the distance of the fiber's tip to the silicon detector surface to $10 \mu \mathrm{m}$, reducing the diameter of the beam to $9 \mu m$ (direct beam) and $57 \mu m$ (reflected beam). See Figure 7 for details.

Another feature, as noted earlier, is the use of an external PIN diode mounted on a BNC coaxial connector with isolated ground, as shown in Figure 2, to test the integrity of the optical fiber, specially of its tip, that can be easily broken or scratched. An accident of this nature already took place before we added the FC/PC connector. The result was a large spread of light over the detector. In Figure 12, we show the damaged tip over a $50 \mu \mathrm{m}$ pitch silicon strip detector. The external PIN diode used is an EG\&G FFD-100. Its sensitivity at $870 \mathrm{~nm}$ is $1.47 \mathrm{~A} / \mathrm{W}$, measured with a calibrated light source, the Photodyne Fiber Optic Test Set model 2275XQ. We used two LED sources, one at $870 \mathrm{~nm}$ and the other at 1300 $\mathrm{nm}$. The latter one gave a weak response at the noise level. The sensitivity measured at 870 $\mathrm{nm}$ for the Motorola PIN diode MFOD 1100 is $1.1 \mathrm{~A} / \mathrm{W}$, but it is faster than FFD-100 by 
approximately a factor of two[9]. The expected sensitivity at $1062 \mathrm{~nm}$, extrapolated from Figure 8, is $0.3 \mathrm{~A} / \mathrm{W}$ for the FFD-100, and $0.2 \mathrm{~A} / \mathrm{W}$ for the MFOD1100.

The rise time at $50 \Omega$ was measured by observing the response of the FFD-100 on an oscilloscope (Tektronix DSA 602A) to a 10 ns LASER pulse. In Figure 9 we show this response. In Figure 10, the response of the internal PIN diode is shown indicating that it is damaged. From Figure 9 we conclude that the rise time of the PIN diode's response is 3 ns.

Preliminary measurements on a Moscow State University (MSU) strip detector, using a setup described in Reference 8, shows a good performance of the pulsed LASER light source for this application. We have also tested the pulsed LASER at the CDF SVX' silicon detectors. In Figure 11a we show the oscilloscope picture of the SVX chip readout. The highest level corresponds to the strip the LASER is illuminating. Two lower levels on both sides of it are the responses from the neighboring strips. The same picture at a larger time scale is shown in Figure $11 \mathrm{~b}$. There one can see the dips at the levels, near the three strips that share the charge, due to capacitive coupling. More detailed information will be presented in another publication[10].

\section{References}

[1] R.Lipton, Silicon Tracker Preliminary Design Report. Fermilab, 1993.

[2] S. Gadomski et. al., SCIPP 92/03, Santa Cruz, California.

[3] EG\&G CANADA, Optoelectronics Div., Catalogs and Datasheets, Canada, 1992. Contact : Jeff Britton, Tel. (514)424-3300, Fax (514)424-3411.

[4] New England Photoconductors, TC1A Thermoelectric Cooler Controller Operator's Manual, EUA, 1992.

[5] Picosecond Pulse Labs, Pulse Generator 2000D Handbook, EUA, 1992.

[6] American National Standards Institute, For the Safe Use of LASERs, ANSI Publication Z136.1-1986, USA, 1986.

[7] Tim Miller, FERMILAB. Private communication.

[8] A.Leflat et. al., First Results from MSU Silicon Strip Detector. Private communication, FERMILAB, 1993 (unpublished).

[9] We thank Jeff Andresen of CD/DA Electronics for letting us to use the calibrated light source 2275XQ. We also thank Ernest Buchanan of AD/PBAR Source for fusing the optical fiber.

[10] The Laser Test setup presented in this report is based on the setup developed originally at John Hopkins University (John Krizmanic et. al.). 


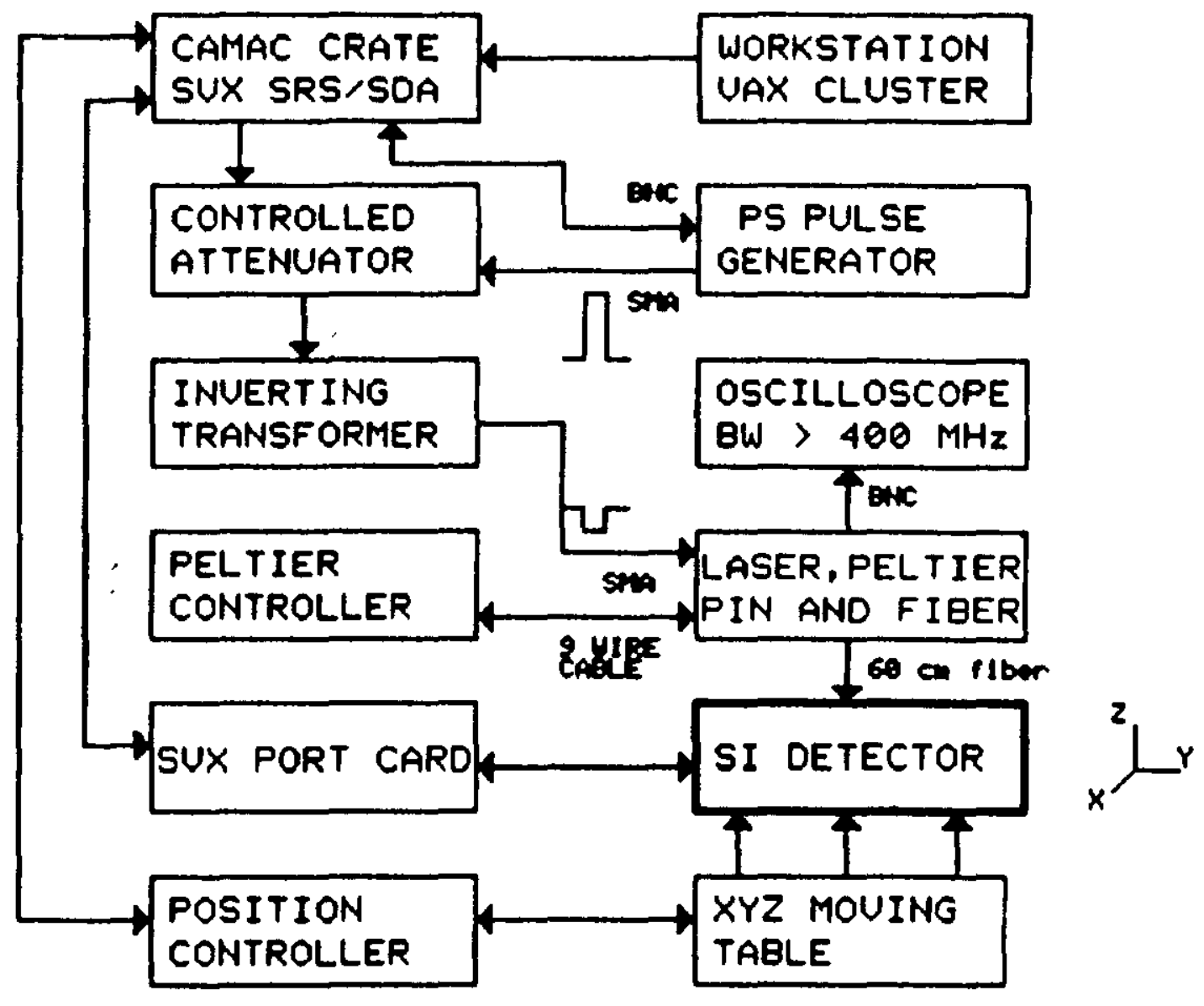

Fig.1 - Si Detector Test LASER Setup 


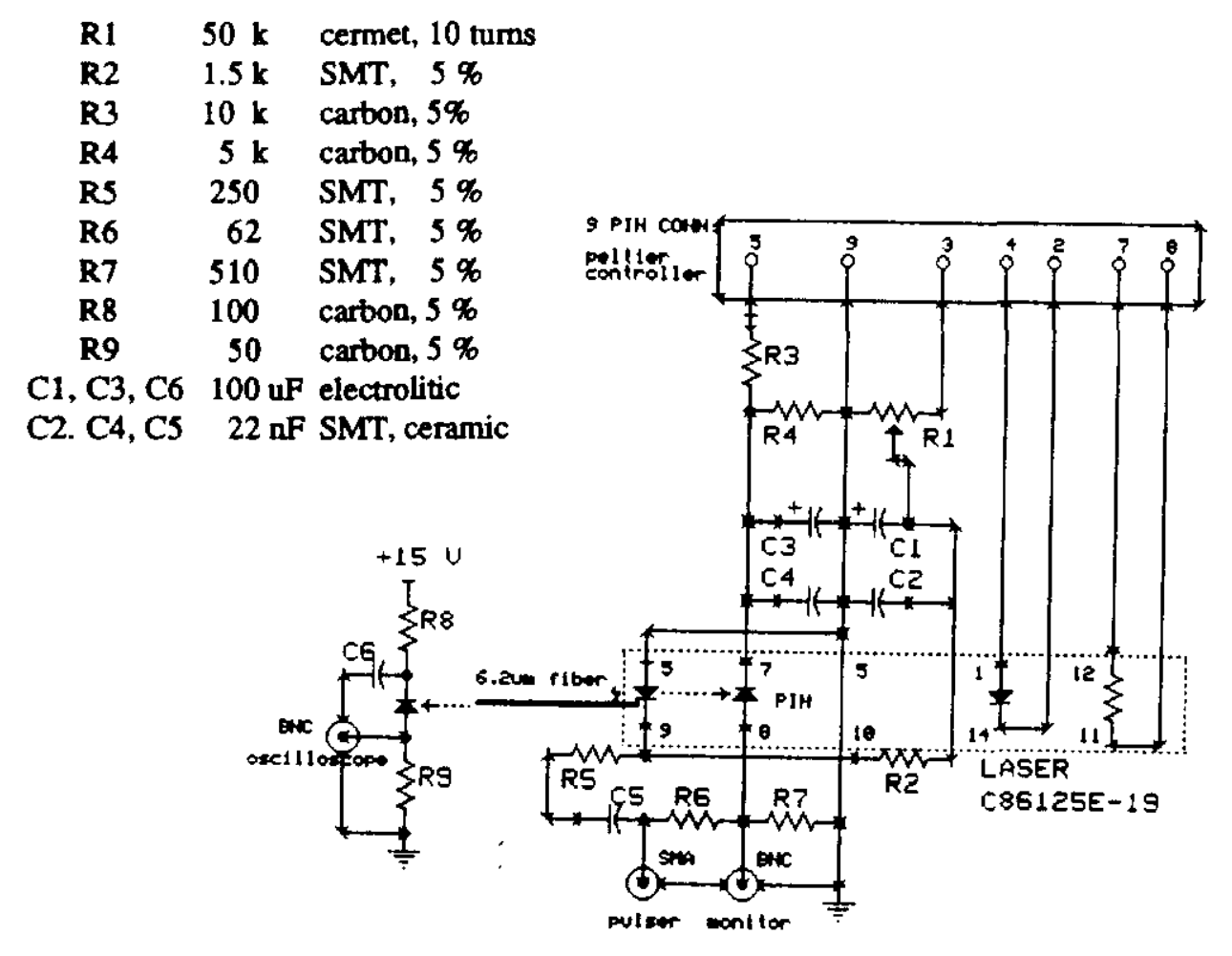

Fig.2 - LASER and Calibrator Schematic

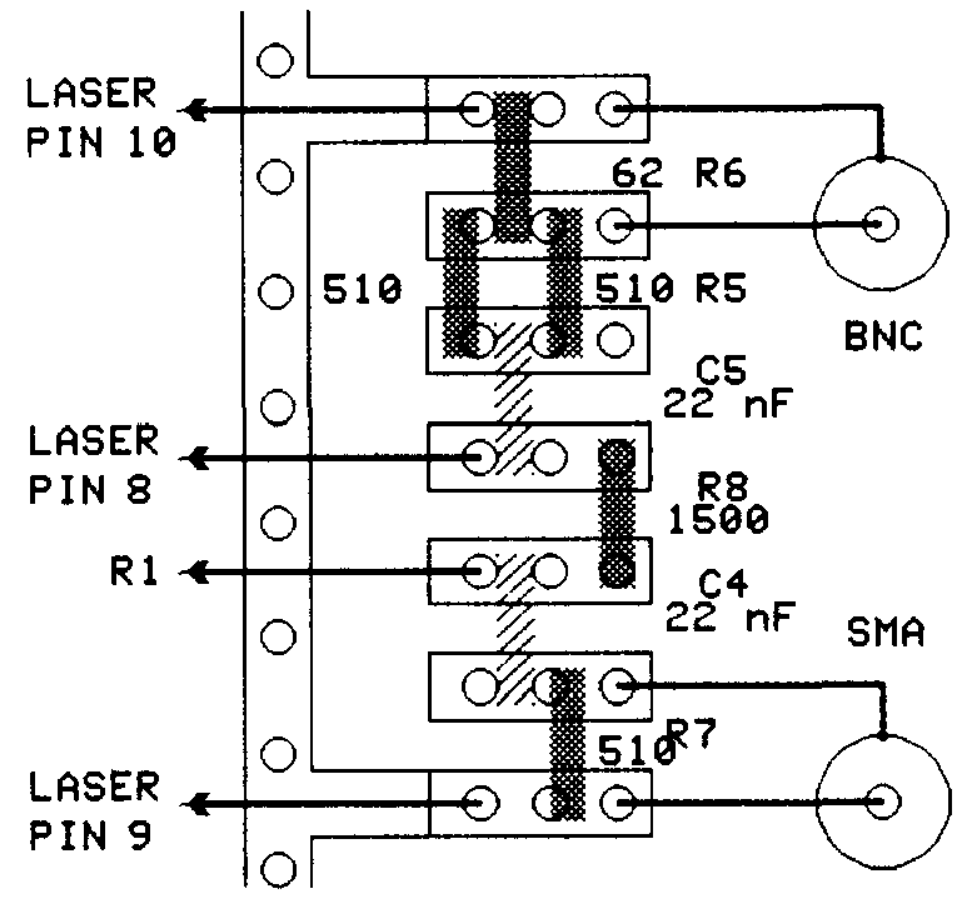

Fig.3 - Layout of SMT Circuit Board 


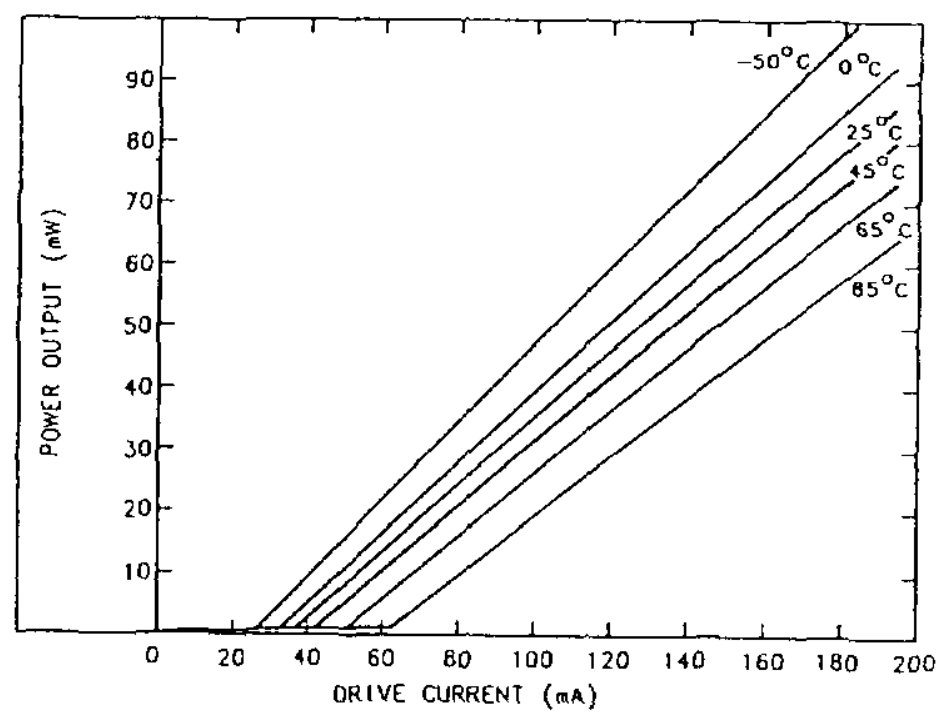

Figure 4a - Power output of C86125 Laser.

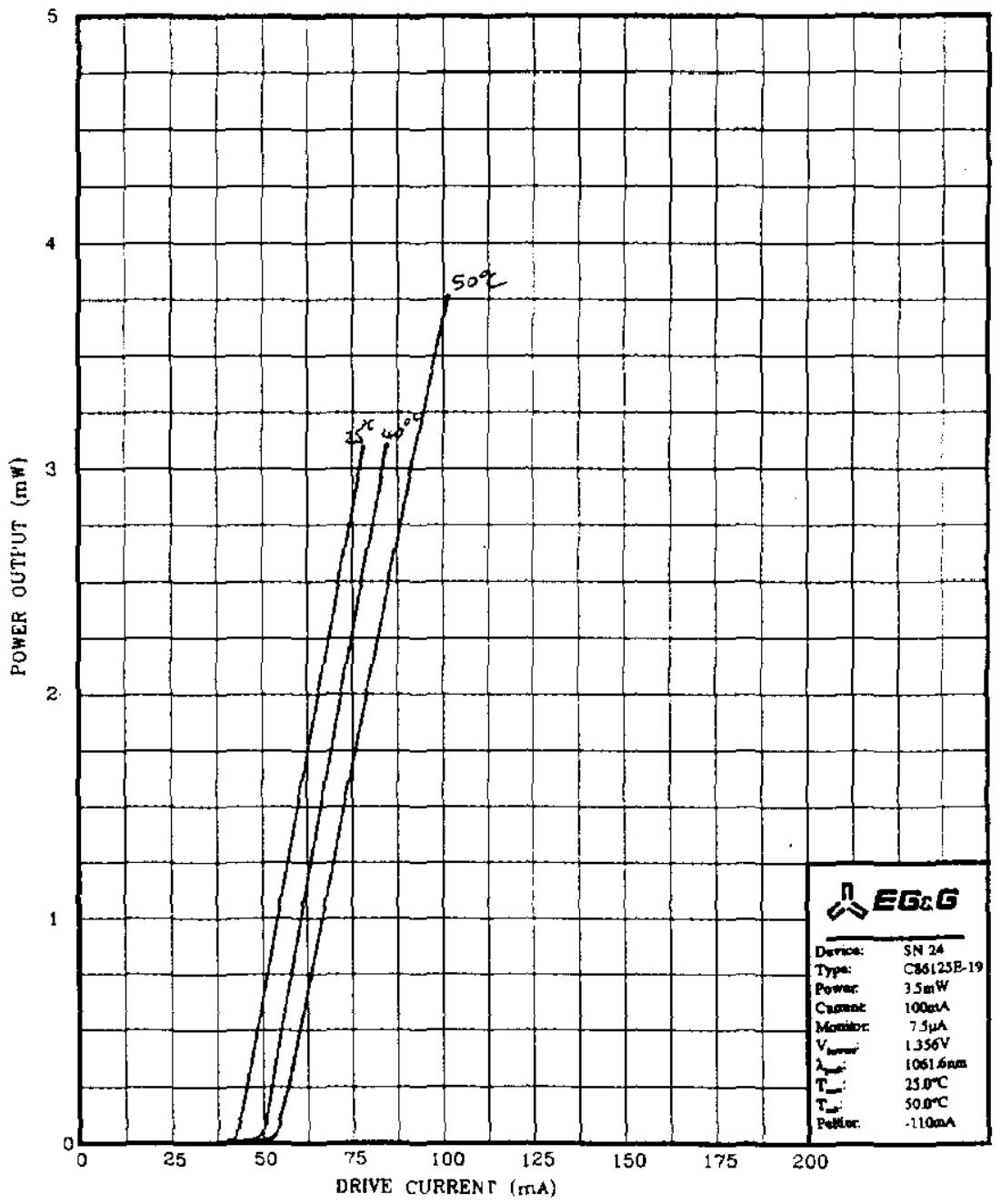

Figure 4b - Power output of C86125E-19 Laser through Flexcore 1060 optical fiber. 
TYPICAL CW CHARACTERISTICS AT $T_{c}=25^{\circ} \mathrm{C}$ (Except as noted)

\begin{tabular}{|c|c|c|c|c|}
\hline $\mathrm{C} 86125 \mathrm{E}$ & & MIN & TYP & MAX \\
\hline Radiant flux output & $\Phi(\mathrm{mW})$ & 50 & & \\
\hline Forward bias curtent at $\Phi$ & $\operatorname{IF}(\mathrm{mA})$ & & 120 & 200 \\
\hline Forward voltage drop & $v_{f}(V)$ & & 1.3 & 2 \\
\hline Threshold current & $\operatorname{Ith}(\mathrm{mA})$ & & 35 & 50 \\
\hline Rise time (Forward bias $I_{t b}$ to $I_{f} \max$.) & $t_{r}(n s)$ & & $<1$ & \\
\hline Wavelength of peak radiant intensity & $\lambda_{0}(\mathrm{~nm})$ & 1059 & & 1069 \\
\hline Spectral bandwidth & $\Delta \lambda(\mathrm{nm})$ & & 0.1 & \\
\hline Wavelength temperature coefficient & $+\left(\mathrm{nm} /{ }^{\circ} \mathrm{C}\right)$ & & 0.32 & \\
\hline Beam spread (50\% peak intensity) & & & & \\
\hline Parallel to junction plane & $\theta||\left(^{\circ}\right)$ & & 10 & \\
\hline Perpendicular to junction plane & $\theta \perp\left(^{\circ}\right)$ & & 40 & \\
\hline Source Size & $\mathrm{WxH}(\mu \mathrm{m})$ & & $3 \times 1$ & \\
\hline
\end{tabular}

Figure 5a - C86125 Laser Spec's.

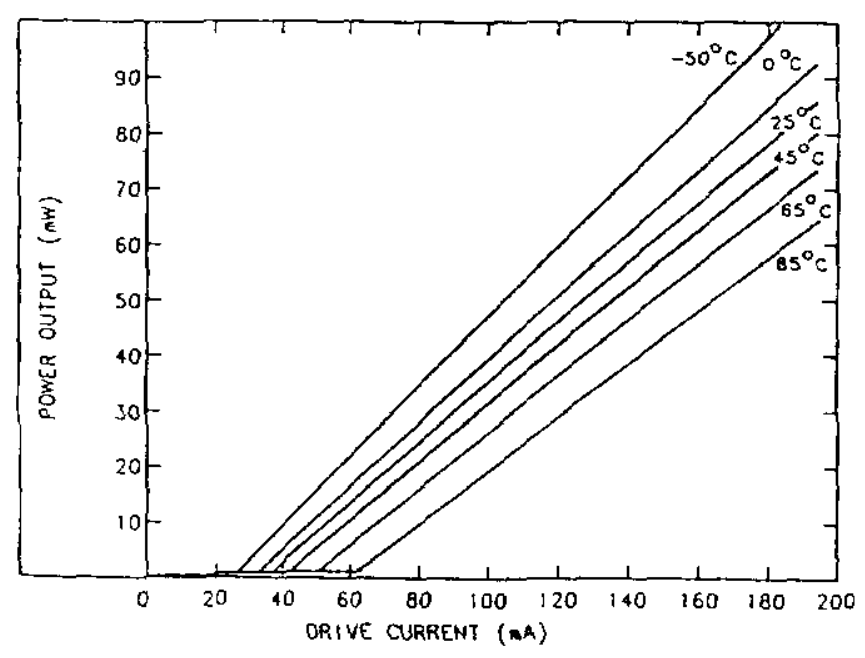

Figure $5 b$ - Power Output vs Drive Current.

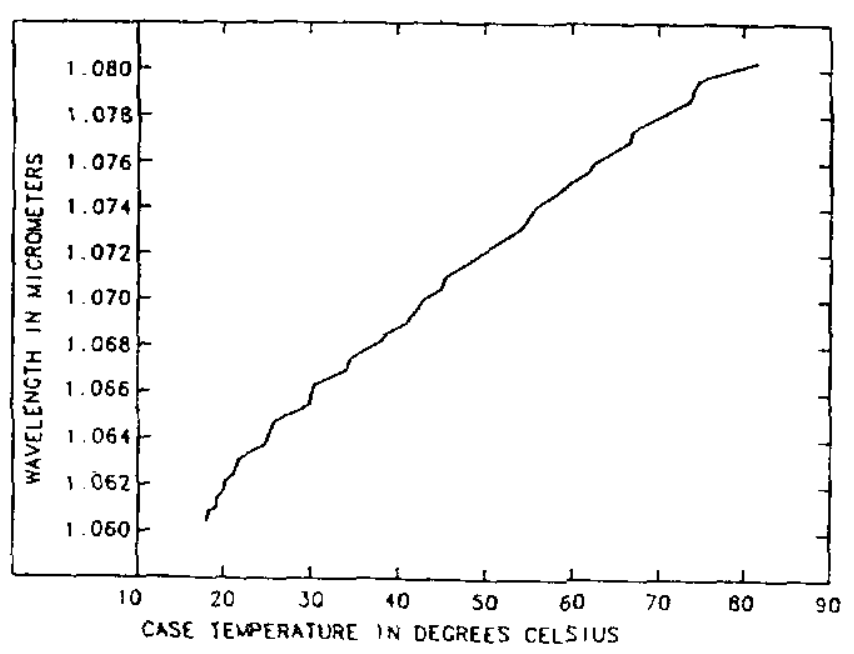

Figure $5 c$ - Peak Wavelength vs Temperature. 


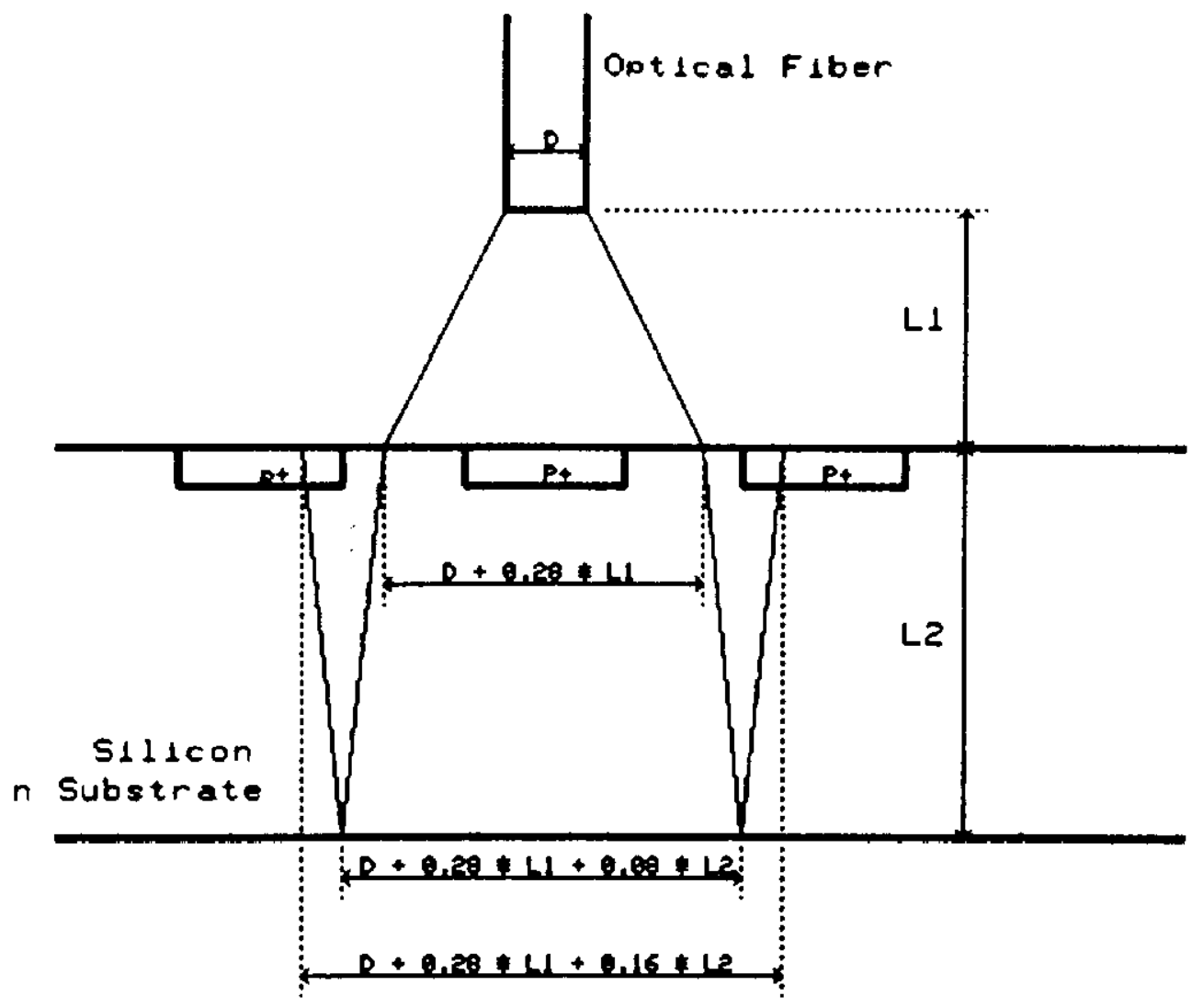

Fig.7 - Light Propagation in Si Detector 


\begin{tabular}{|l|l|l|}
\hline Characteristic & \multicolumn{1}{|c|}{ FFD-100 } & Units \\
\hline Active Area & 5.1 & Sq-mm \\
Spectral Range & $400-1150$ & $\mathrm{~nm}$ \\
Responsivity & 0.6 & $\mathrm{~A} / \mathrm{W}$ at $850 \mathrm{~nm}$ \\
Bandwidth & 150 & $\mathrm{MHz}$ into $50 \mathrm{Ohm}$ \\
Rise Time & 2 & $\mathrm{~ns}$ into $50 \mathrm{Ohm}$ \\
Operating Voltage & $0-100$ & $\mathrm{~V}$ \\
Breakdown Voltage & $>125$ & $\mathrm{~V}$ \\
Capacitance & 8.5 & $\mathrm{pF}$ \\
Dark Current & 5 & $\mathrm{nA}$ \\
Series Resistance & 50 & Ohm \\
Noise Current & 40 & $10 \mathrm{E}-15 \mathrm{~A} /(\mathrm{Hz}) \mathrm{E}-1 / 2$ \\
NEP (850,10 MHz,1) & 66 & $10 \mathrm{E}-15 \mathrm{~W} /(\mathrm{Hz}) \mathrm{E}-1 / 2$ \\
Response Linearity & $<1 \%$ & Over 7 decades \\
Operating Temperature & -55 to 125 & Centigrade \\
Package Style & TO-5 & \\
\hline
\end{tabular}

Figure 8a - Operating Data and Specifications at 23 deg-C: Typical Performance at $15 \mathrm{~V}$.

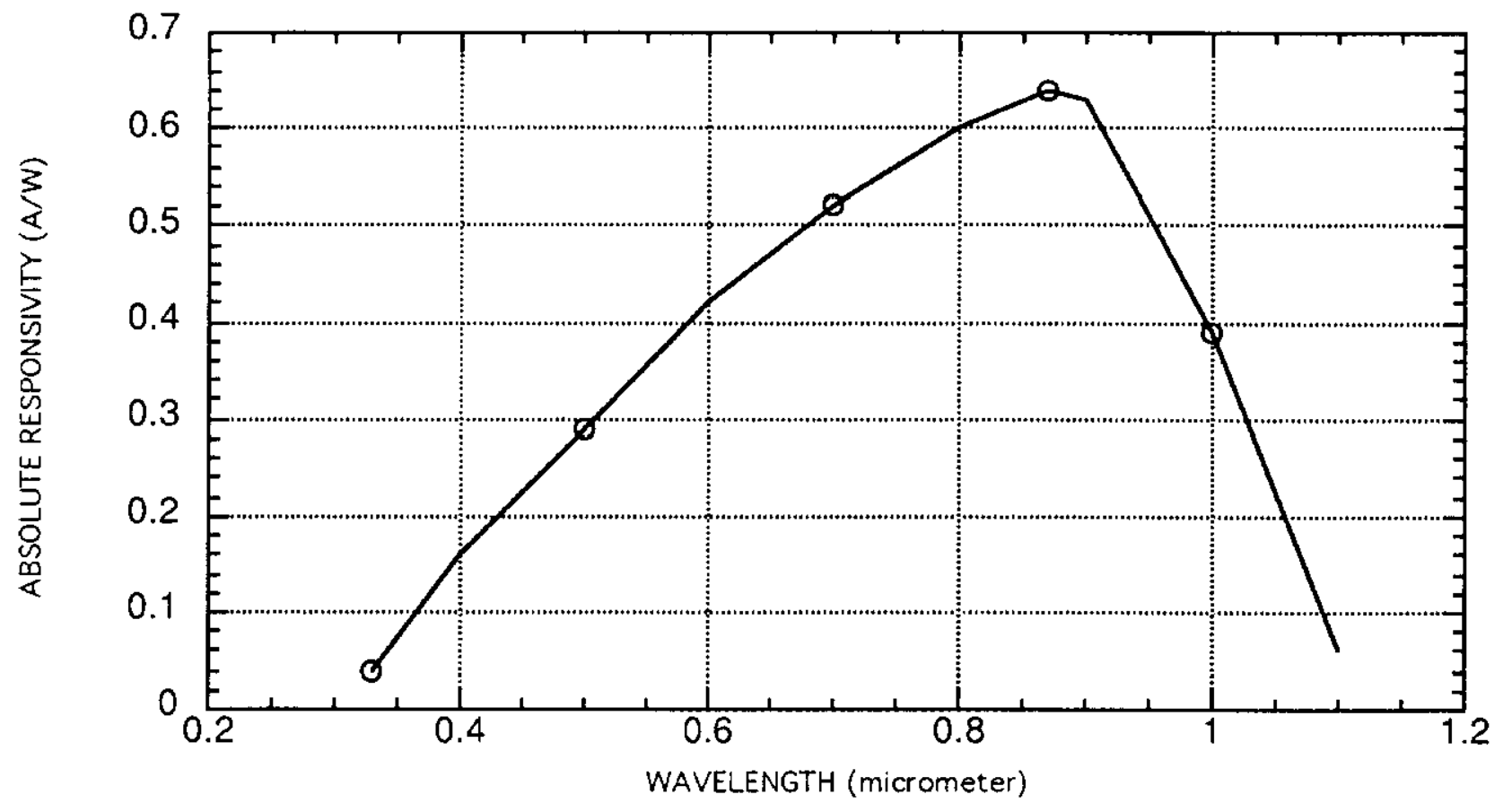

Figure 8b - Typical Spectral Response of FFD-100. 
DSA 602A DIGITIZING SIGNAL ANALYZER

date: 19-JUA-93 t1me: 15: $49: 54$

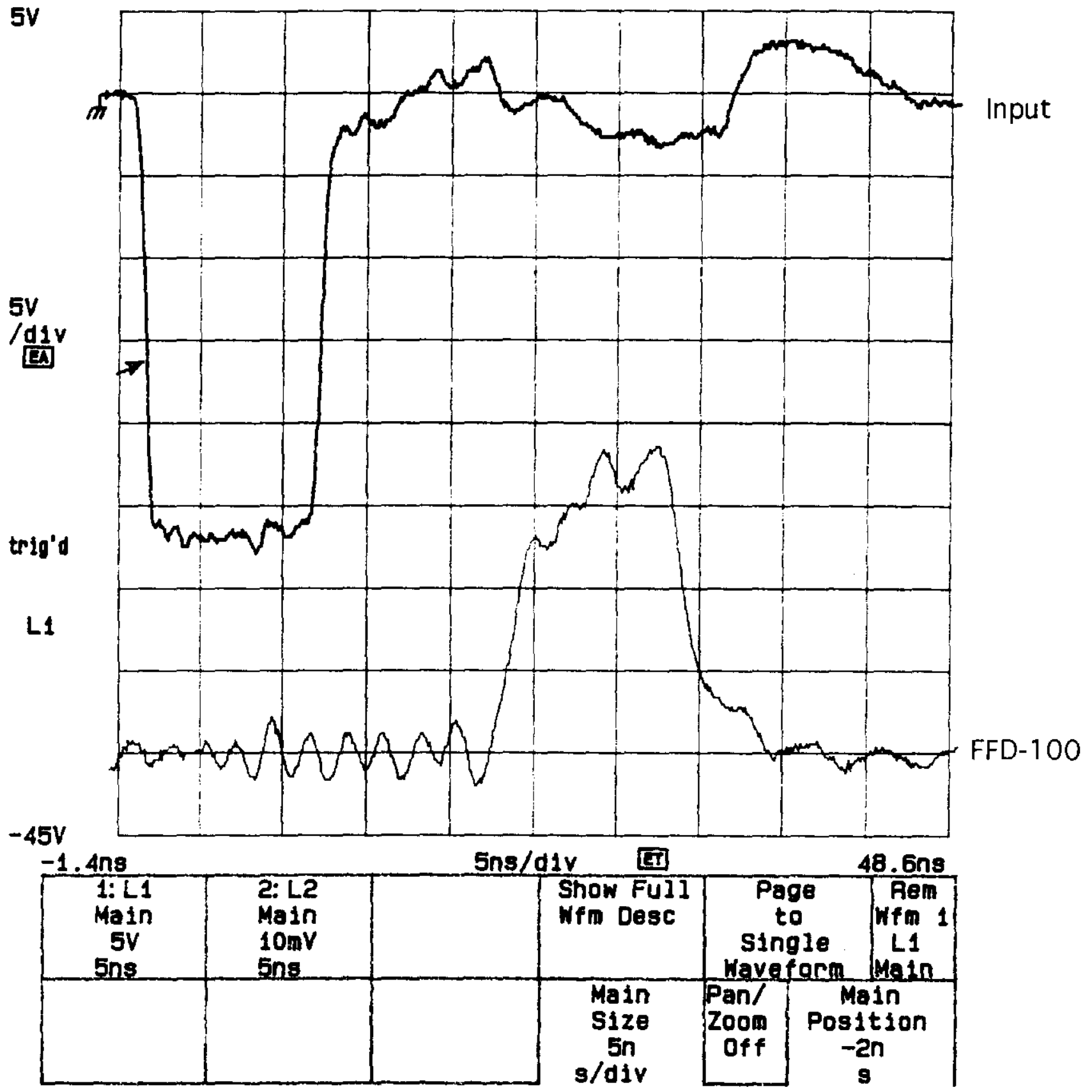

Figure 9 - The response of the PIN diode FFD-100 to a 10 ns laser pulse. 
DSA 602A DIGITIZING SIGNAL ANALYZER

date: 19-llN-93 time: 15: 06: 04

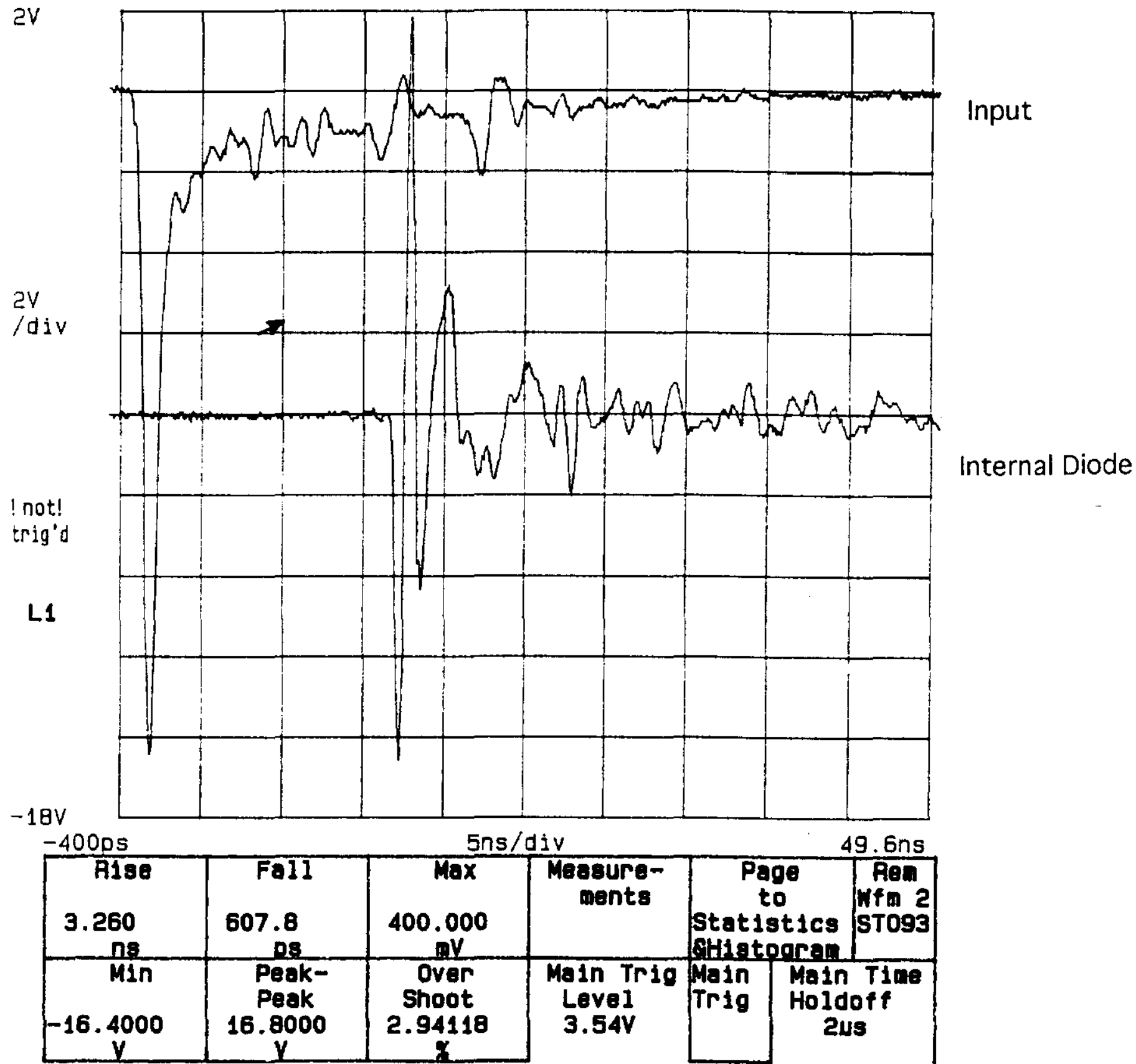

Figure 10 - The response of the internal PIN diode to a laser pulse. 


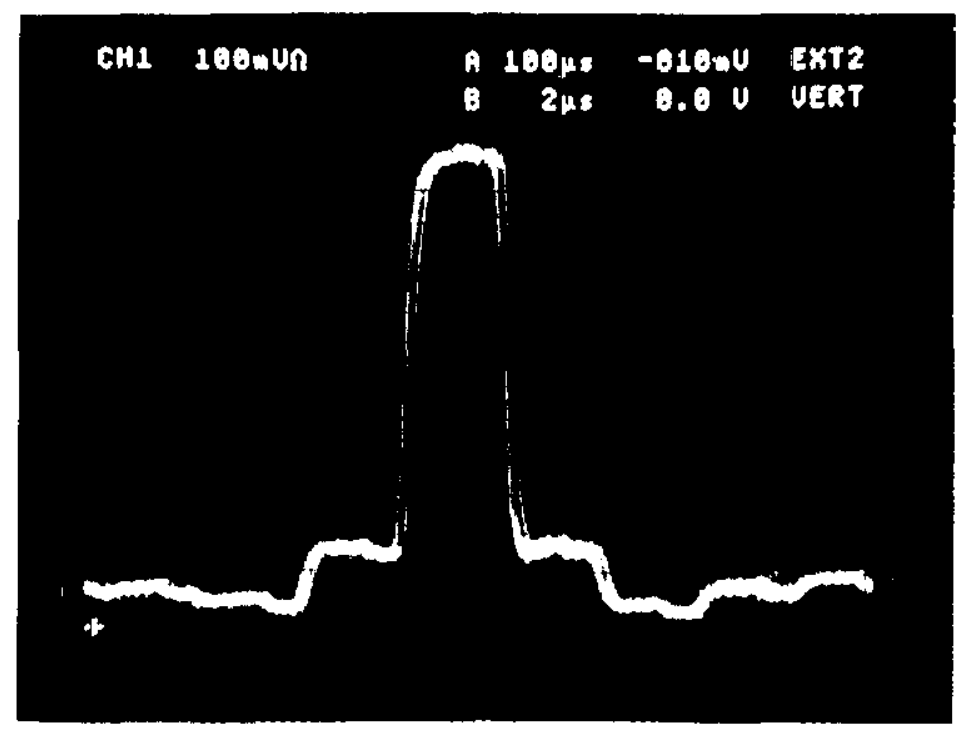

Figure $11 \mathrm{a}-\mathrm{CDF}$ silicon detector response to LASER as seen by SVX readout on oscilloscope.

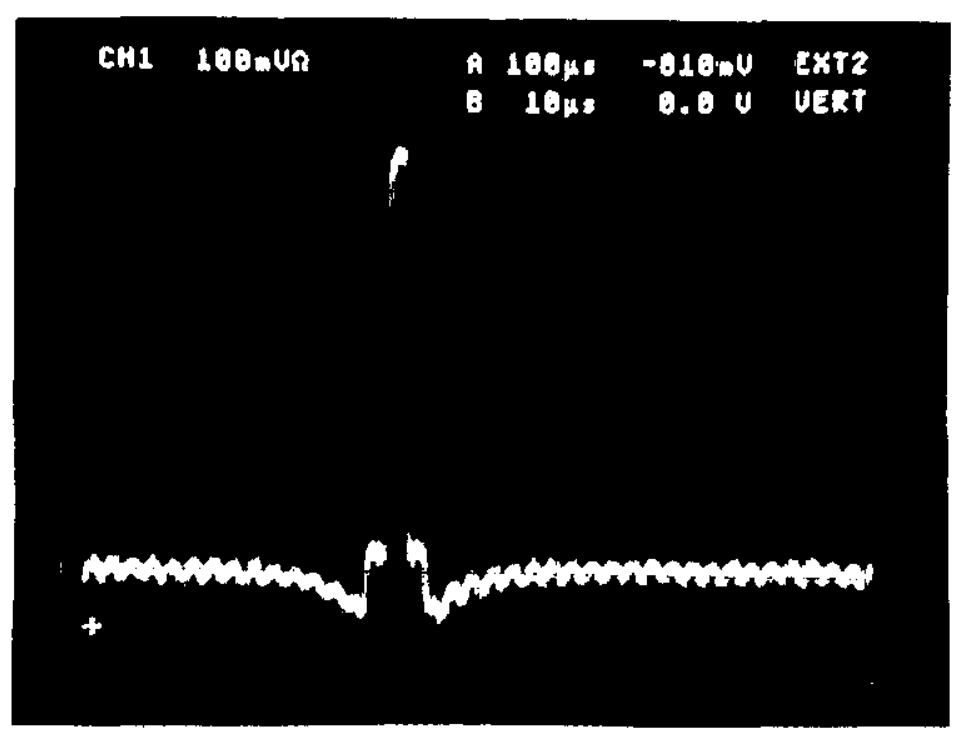

Figure $11 \mathrm{~b}$ - Same as $11 \mathrm{a}$ with a larger time scale of oscilloscope. 


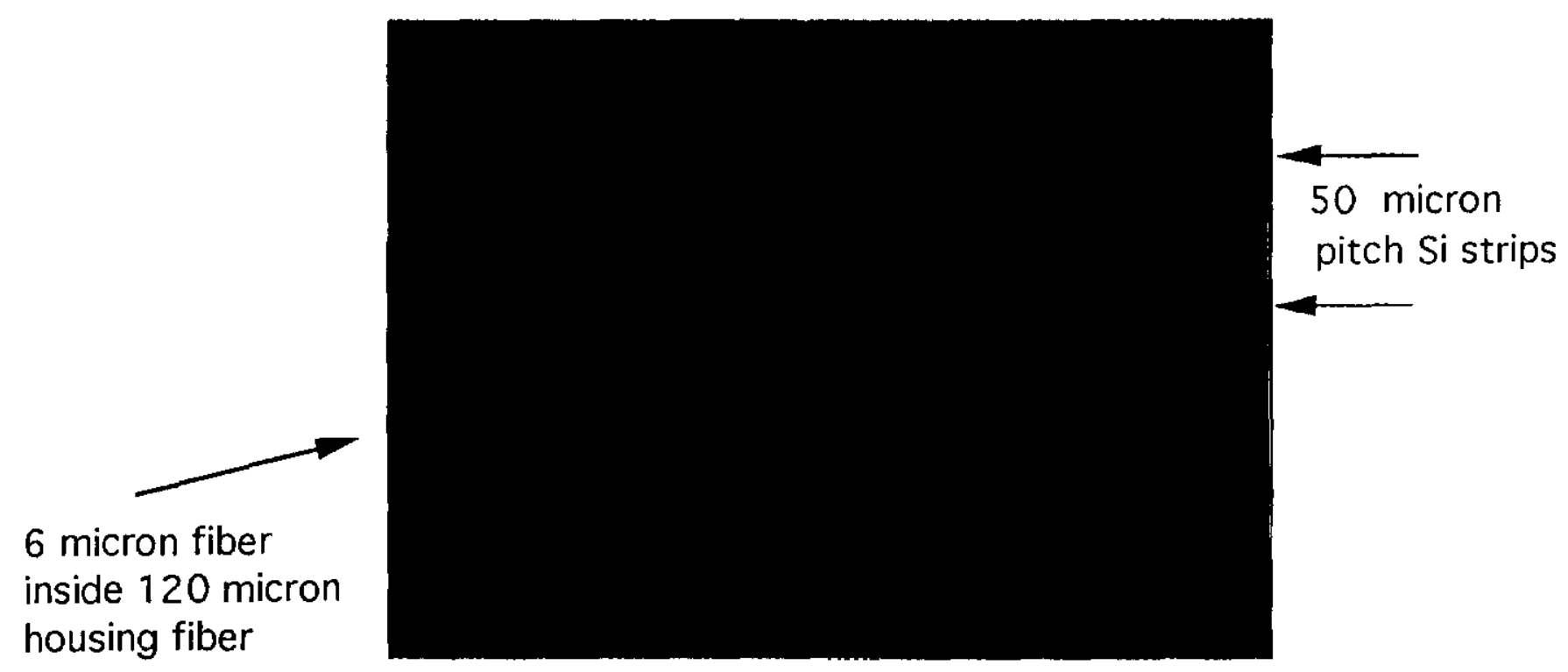

Figure 12 - Broken tip of the optical fiber over a Si strip detector 